\title{
Prevalence and pattern of cardiovascular-related causes of out-of- hospital deaths in Lagos, Nigeria
}

\author{
Oluseyi Adegoke ${ }^{1}$, Nicholas Awodele Awolola², Jayne Ngozi Ajuluchukwu ${ }^{3}$
}

1. College of Medicine, University of Lagos, Nigeria, Department of Medicine.

2. College of Medicine, University of Lagos, Nigeria, Anatomic and Molecular Pathology Department.

3. College of Medicine, University of Lagos, Medicine.

\begin{abstract}
Background: In developed countries 50\% - 75\% of deaths from cardiovascular-diseases occurs out-of-hospital. In Nigeria where patronage of orthodox health facilities is low, the impact of cardiovascular-related diseases on out-of-hospital mortality has been sparsely studied.

Objectives: To determine the prevalence and pattern of cardiovascular-related causes of out-of-hospital deaths in Lagos, Nigeria.

Methods: A 5-year retrospective review of all autopsied medical decedents brought-in-dead (BID) to a Nigerian tertiary health facility to identify cardiovascular-related causes of death.

Results: A total of 90 cardiovascular-related deaths out of 176 medical BID cases were identified, giving a prevalence of $51.1 \%$. Mean age was $65.2 \pm 15.6$ years. Male: Female ratio was 1.4: 1 , the females were older $(68.29 \pm 14.89)$ vs $(61.63 \pm 15.55)$ years. Age group $>60$ years accounted for $63.3 \%$ of deaths. Commonest primary diseases were hypertensive heart disease $(48.9 \%)$ and cerebrovascular accident (24.4\%). Myocardial infarction occurred in 8.9\%. Heart failure, cerebral dysfunction and unspecified circulatory collapse were the causes of death in $54.4 \%, 23.3 \%$ and $14.4 \%$ respectively.

Conclusion: Cardiovascular-related diseases are major contributors to out-of-hospital medical deaths occurring chiefly in those $>60$ years. Hypertensive heart disease and heart failure are the greatest contributors to this cardiovascular-related disease mortality.
\end{abstract}

Keywords: Pattern of out-of-hospital deaths, brought-in-dead (BID), cardiovascular-related disease mortality in Nigeria.

DOI: https://dx.doi.org/10.4314/ahs.v18i4.13

Cite as: Adegoke O, Awolola NA, Ajuluchukwu JN. Prevalence and pattern of cardiovascular-related causes of out-of- hospital deaths in Lagos, Nigeria. Afri Health Sci. 2018;18(4): 942-949. https:// dx.doi.org/10.4314/ahs.v18i4.13

\section{Introduction}

In 2008, 63\% of global deaths were reported due to non-communicable-diseases, $48 \%$ of which were due to cardiovascular-related-diseases alone. ${ }^{1}$ Over $80 \%$ of those deaths from cardiovascular-diseases occurred in developing countries, with majority being in those below

\section{Corresponding author:}

Oluseyi Adegoke,

College of Medicine, University of Lagos,

Nigeria, Department of Medicine.

Email: oluseyigoke@yahoo.com
70 years of age. ${ }^{1}$ Though cardiovascular-diseases contributed only $8.8 \%$ of the deaths recorded in sub-Saharan Africa, ${ }^{2}$ the global mortality burden from cardiovascular-diseases has been projected to increase by $20 \%$ by year 2020 with the greatest contribution expected from regions such as sub-Saharan Africa. ${ }^{1}$ The spectra of and associated mortalities from cardiovascular-diseases however differ between sub-Saharan Africa and developed western countries. While coronary-artery-disease (CAD) is the main cause of death in developed countries ${ }^{3}$ and the leading cause of death among black Americans, ${ }^{4}$ stroke was the leading cardiovascular cause of death in sub-Saharan Africa. ${ }^{2}$ Hypertensive heart disease and heart failure are also commonly reported cardiovascular causes

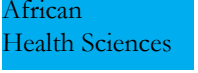

C) 2018 Adegoke et al. Licensee African Health Sciences. This is an Open Access article distributed under the terms of the Creative commons Attribution License (https://creativecommons.org/licenses/BY/4.0), which permits unrestricted use, distribution, and reproduction in any medium, provided the original work is properly cited. 
of death in sub-Saharan Africa. ${ }^{5} \mathrm{CAD}$ is considered to be relatively rare in sub-Saharan Africa, although low but rising prevalence have been reported. ${ }^{5,6,7}$ Most of those studies were however hospital based and were conducted in late 1990 s to early 2000 s.

It is known that CAD is associated with high mortality, majority of which occur outside the hospital. ${ }^{5,8}$ In developed countries, $50 \%-75 \%$ of deaths from cardiovascular-disease events occur out-of-hospital. ${ }^{8}$ In Western Nigeria, $86.1 \%$ of sudden-cardiac-deaths occurred out-of-hospital. ${ }^{9}$ Low patronage of orthodox hospitals in Nigeria may contribute to more out-of-hospital deaths. ${ }^{10}$ It is therefore possible that some cases of CAD never got to the hospital. Data on out-of-hospital mortality is sparse in this environment. In one centre in Nigeria, CAD prevalence in coroner's autopsy was $1.6 \%$ while only 41 clinical cases out of 110,000 patients were seen. ${ }^{11}$ Mortality rate from CAD was expected to double between 1990 and 2020 with about $82 \%$ of the contribution from developing countries. ${ }^{12}$

It is therefore pertinent to review the mortality burden posed by cardiovascular-related diseases among out-of-hospital Nigerian-decedents who may have been left out in clinical reviews. It is believed that the data generated from this study would give a broader view of the burden of cardiovascular diseases beyond that obtained from hospital based mortality and assist in making informed health policy.

The aim of this study was to determine the prevalence and pattern of cardiovascular- related causes of out-of-hospital deaths in Lagos, Nigeria.

\section{Methodology \\ Study design}

This was a 5-year retrospective, descriptive study conducted at the Lagos University Teaching Hospital (LUTH), a tertiary health facility situated in Lagos: a cosmopolitan city of Nigeria. The study period was from September $1^{\text {st }}$ 2011 to $31^{\text {st }}$ August 2016. Ethical clearance was obtained from the Health Research Ethics Committee of the hospital.

\section{Subjects}

These were all decedents 'brought-in-dead' (BID) to LUTH during the period of study. LUTH receives referrals from all over Lagos metropolis and the surrounding states. BID cases are first taken to the emergency department of the hospital where registration processes occur, death is confirmed, and permission for transfer to the Anatomic and Molecular Pathology Department of the hospital (AMPD) for autopsy is obtained from the next of kin. Some decedents are taken by relatives, directly to the AMPD mortuary for storage and autopsies are performed in situations where there was no prior death certification. Registration records of such decedents are entered into the 'home register' of the AMPD.

\section{Inclusion criteria}

All decedents $\geq 18$ years of age that were brought-indead from suspected medical causes.

\section{Exclusion criteria}

\section{Deaths that occurred within hospital setting.}

Deaths related to surgery, obstetrics and gynaecology, or trauma (such as gun shots, road traffic accidents or assaults).

\section{Operational definitions}

"Brought-in-Dead" (BID) in this study refers to decedents whose deaths occurred before arrival at the hospital.

Medical cause of death refers to non-traumatic, non-surgical, non-obstetrics and gynaecology related cause of death.

Primary Disease refers to the underlying-proximate cause of death. It is defined as the disease or event that started the chain of events that led to death. ${ }^{13}$

Cause of death is either a consequence or complication of the primary cause, which might have contributed to the death of the person. ${ }^{14}$

Cardiovascular-related cause of death in this study refers to "total cardiovascular disease" as defined by the International Classification of Diseases-10 (ICD-10). ${ }^{15}$

'Cerebral dysfunction' includes autopsy finding of brain tonsillar herniation, cerebral haemorrhage, thrombosis, and/or oedema. 
'Complete autopsy report' refers to availability of detailed records of the primary disease, cause of death, gender and age.

\section{Data collection method}

The emergency department death register and the 'home register' of the AMPD were reviewed to identify decedents brought-in-dead from suspected medical causes. The data collected included age, gender, date and time of presentation/death. A simple proforma was prepared for data entry. Records of all identified autopsied medical BID cases were then retrieved from the autopsy register at the AMPD. Data retrieved from the register included the primary diseases and causes of death as assigned by the supervising consultant Pathologists. Data of decedents with cardiovascular-related cause of death were then retrieved and included in the study.

\section{Data management and statistical analysis}

Data was entered into excel sheet for cleaning and imported into the Statistical Package for Social Sciences(SPSS) version 20.0 for analysis. Continuous variables were expressed as means with standard deviations. Categorical variables were expressed as frequencies with percentages.

\section{Results}

There were 320 suspected medical BID cases deposited during the period of study. Only 176 of these had complete autopsy reports, out of which 90 were found to have cardiovascular-related causes of death giving a prevalence of $51.1 \%$.

\section{Characteristics of the study population}

Table 1 shows the characteristics of the study population.

Table 1: Characteristics of the study population

\begin{tabular}{cc}
\hline Characteristic & No(\%) \\
\hline Gender & $48(53.3)$ \\
Male & $42(46.7)$ \\
Female & \\
& \\
Age groupin years & $0(0)$ \\
$<20$ & $7(7.8)$ \\
$21-40$ & $26(28.9)$ \\
$41-60$ & $57(63.3)$ \\
$>60$ &
\end{tabular}

The 90 cases studied comprised males and females in ratio 1.4: 1 . Their age ranged from 33 to 101 years with a mean of $65.2 \pm 15.6$ years. The mean ages of the female

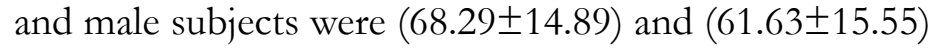
years, respectively.
Primary cardiovascular-related diseases of the study population

Table 2 shows the distribution of the primary cardiovascular-related diseases in the study population. The most frequent primary cardiovascular-related diseases were hypertensive heart disease and cerebrovascular accident. More than half of the subjects with hypertensive heart disease were males. A pertinent observation is that $50 \%$ $75 \%$ of all the primary diseases occurred in the $>60$ years age group. Among the uncommon diseases were 2 cases of hypertrophic cardiomyopathy. 
Table 2: Primary diseases of the study population by gender and agegroup.

\begin{tabular}{lcccccc}
\hline Primary cardiovascular disease & Total & & & \multicolumn{3}{c}{ Age groups (years) } \\
\cline { 6 - 8 } & population & Males & Females & $21-40$ & $41-60$ & $>60$ \\
& $\mathrm{~N}=90$ & $\mathrm{~N}=48$ & $\mathrm{~N}=42$ & $\mathrm{~N}=7$ & $\mathrm{~N}=26$ & $\mathrm{~N}=57$ \\
& $\mathrm{n}(\%)$ & $\mathrm{n}(\%)$ & $\mathrm{n}(\%)$ & $\mathrm{n}(\%)$ & $\mathrm{n}(\%)$ & $\mathrm{n}(\%)$ \\
\hline Hypertensive heart disease & $44(48.9)$ & $26(54.1)$ & $18(40.9)$ & $2(4.5)$ & $13(29.5)$ & $29(65.9)$ \\
Cerebrovascular-Accident & $22(24.4)$ & $11(50.0)$ & $11(50.0)$ & $4(18.2)$ & $6(27.3)$ & $12(54.5)$ \\
Myocardial-Infarction & $8(8.9)$ & $4(50.0)$ & $4(50.0)$ & $0(0)$ & $2(25.0)$ & $6(75.0)$ \\
Heart-Failure & $8(8.9)$ & $2(25.0)$ & $6(75.0)$ & $0(0)$ & $2(25.0)$ & $6(75.0)$ \\
Cardiomyopathies & $6(6.7)$ & $4(66.7)$ & $2(33.3)$ & $0(0)$ & $3(50)$ & $3(50)$ \\
Atherosclerosis & $1(1.1)$ & $1(100)$ & $0(0)$ & $0(0)$ & $0(0)$ & $0(0)$ \\
Pulmonary-Hypertension & $1(1.1)$ & $0(0)$ & $1(100)$ & $1(100)$ & $0(0)$ & $0(0)$ \\
\hline
\end{tabular}

Causes of death of the study population

The causes of death in the study population are shown in Table 3.
Heart failure was the commonest cause of death seen. Hypertensive heart failure accounted for more than half $(57.1 \%)$ of all the heart failure cases.

Table 3: Causes of death of the study population by gender and agegroup.

\begin{tabular}{lcccccc}
\hline Causes of death & Total & & & \multicolumn{4}{c}{ Age groups (years) } \\
\cline { 6 - 7 } & Population & Males & Females & $21-40$ & $41-60$ & $>60$ \\
& $\mathrm{~N}=90$ & $\mathrm{~N}=48$ & $\mathrm{~N}=42$ & $\mathrm{~N}=7$ & $\mathrm{~N}=26$ & $\mathrm{~N}=57$ \\
& $\mathrm{n}(\%)$ & $\mathrm{n}(\%)$ & $\mathrm{n}(\%)$ & $\mathrm{n}(\%)$ & $\mathrm{n}(\%)$ & $\mathrm{n}(\%)$ \\
\hline Heart Failure & $49(54.4)$ & $28(57.1)$ & $21(42.9)$ & $1(2.0)$ & $14(28.6)$ & $34(69.4)$ \\
$\begin{array}{l}\text { Cerebral } \\
\text { Dysfunction }\end{array}$ & $21(23.3)$ & $13(61.9)$ & $8(38.1)$ & $3(14.3)$ & $7(33.3)$ & $11(52.4)$ \\
$\begin{array}{l}\text { Unspecified } \\
\text { circulatory collapse }\end{array}$ & $13(14.4)$ & $4(30.8)$ & $9(69.2)$ & $3(23.1)$ & $4(30.8)$ & $6(46.2)$ \\
$\begin{array}{l}\text { Respiratory Failure } \\
\text { Renal Failure }\end{array}$ & $4(4.4)$ & $3(75.0)$ & $1(25.0)$ & $0(0)$ & $0(0)$ & $4(100.9)$ \\
$\begin{array}{l}\text { Pulmonary } \\
\text { Embolism }\end{array}$ & $2(2.2)$ & $0(0)$ & $2(100.0)$ & $0(0)$ & $0(0)$ & $2(100.0)$ \\
\hline
\end{tabular}


Table 4 shows the relationship between the primary diseases and causes of death.

Heart failure was the cause of death in $28(63.6 \%)$ of sub- jects with hypertensive heart disease and in $7(87.5 \%)$ of subjects with myocardial infarction, while cerebral dysfunction was the commonest $17(77.3 \%$ ) cause of death in subjects with cerebrovascular-accident.

Table 4: Relationship of the primary disease to cause of death of the study population.

\begin{tabular}{lccccccc}
\hline Primary diseases & \multicolumn{7}{c}{ Causes of death } \\
\cline { 2 - 7 } & $\begin{array}{c}\text { Heart } \\
\text { Failure }\end{array}$ & $\begin{array}{c}\text { Cerebral } \\
\text { Dysfunction }\end{array}$ & $\begin{array}{c}\text { Undefined } \\
\text { Circulator } \\
\text { y collapse }\end{array}$ & $\begin{array}{c}\text { Respiratory } \\
\text { Failure }\end{array}$ & $\begin{array}{c}\text { Renal } \\
\text { Failure }\end{array}$ & $\begin{array}{c}\text { Pulmonary } \\
\text { Embolism }\end{array}$ & Total \\
\hline $\begin{array}{l}\text { Hypertensive Heart } \\
\text { Disease, N(\%) }\end{array}$ & $28(63.6)$ & $4(9.1)$ & $9(20.5)$ & $1(2.3)$ & $2(4.5)$ & $0(0)$ & $44(100)$ \\
$\begin{array}{l}\text { Cerebrovascular } \\
\text { Accident, N(\%) }\end{array}$ & $0(0)$ & $17(77.3)$ & $2(9.1)$ & $2(9.1)$ & $0(0)$ & $1(4.5)$ & $22(100)$ \\
$\begin{array}{l}\text { Myocardial } \\
\text { Infarction,N(\%) }\end{array}$ & $7(87.5)$ & $0(0)$ & $1(12.5)$ & $0(0)$ & $0(0)$ & $0(0)$ & $8(100.0)$ \\
Heart Failure,N(\%) & $8(100.0)$ & $0(0)$ & $0(0)$ & $0(0)$ & $0(0)$ & $0(0)$ & $8(100.0)$ \\
Cardiomyopathies,N(\%) & $6(100.0)$ & $0(0)$ & $0(0)$ & $0(0)$ & $0(0)$ & $0(0)$ & $6(100.0)$ \\
$\begin{array}{l}\text { Atherosclerosis, } \\
\mathrm{N}(\%)\end{array}$ & $0(0)$ & $0(0)$ & $0(0)$ & $1(100.0)$ & $0(0)$ & $0(0)$ & $1(100.0)$ \\
$\begin{array}{l}\text { Pulmonary } \\
\text { Hypertension,N(\%) }\end{array}$ & $0(0)$ & $0(0)$ & $1(100.0)$ & $0(0)$ & $0(0)$ & $0(0)$ & $1(100.0)$ \\
\hline
\end{tabular}

\section{Discussion}

The impact of cardiovascular-related diseases on out-of-hospital mortality in Nigeria has been sparsely studied. Cardiovascular-related diseases were responsible for $51.1 \%$ of all autopsied out-of-hospital medical deaths in our study. This closely corresponds to the global prevalence of $48 \%$ reported by the WHO but is much higher than the average $8.8 \%$ deaths reported to be due to cardiovascular-related diseases in sub-Saharan Africa. ${ }^{1,2}$ This difference may be due to differences in the period of study; whereas the sub-Saharan African review was done between 1990 and 2010, our review was from 2011 to 2016. Also their estimation was based on all deaths while ours was denominated on deaths from cardiovascular-related diseases only. The higher prevalence in our study may also be related to the WHO expected $20 \%$ rise in cardiovascular-disease mortality by year 2020 with the greatest contribution expected to be from developing countries. ${ }^{1}$ The mean age of our study subjects is in keeping with the WHO report of the probability of cardiovascular disease related deaths occurring before age 70 years in Nigerians. ${ }^{16}$ It is however higher than the mean age of $50.7 \pm 17.5$ years that was recorded for in-hospital medical emergency mortality of the same institution. ${ }^{17}$ This probably suggests that medical attention may be sought more promptly for younger people than it is for the older. The mean age of our study population also corresponds to the retirement age in Nigeria ${ }^{18}$ hence there may be limitation in financial capability which in turn may limit ability to access health-care as desired. Our finding of significantly older females compared to the males is in keeping with the later year of onset of cardiovascular diseases that has been observed in women. ${ }^{19}$

The predominance of hypertensive heart disease and heart failure as causes of death in this study is likely a reflection of the increasing prevalence of hypertension, the low level of awareness of hypertension status and low prevalence of treatment in the country. ${ }^{20,21}$ Our finding is similar to that reported in some studies of coroner's autopsy of sudden death in Nigeria. ${ }^{9,22-24}$ Our observed higher frequency of hypertensive heart disease in males 
also corresponds with the reported higher prevalence of hypertension in males with increasing age in Nigeria. ${ }^{20,21}$ Hypertensive heart failure accounted for more than half of all the heart failure cases in our study which compares with a report from another study in which hypertensive heart failure accounted for $73.3 \%$ of cardiovascular cause of sudden death while all heart failure accounted for $80 \% .{ }^{22}$ Almost two-thirds of our subjects who died of heart failure were older than 60 years, in keeping with the reported higher prevalence of heart failure in older individuals in whom the symptoms are also often atypical, or absent. ${ }^{25}$ This results in low awareness and low health-seeking behaviour, ${ }^{26}$ which may explain why our subjects' deaths had occurred out-of-hospital.

Our finding of Cerebrovascular-accident and cerebral dysfunction as the distant second commonest causes of death contrasts with reports from in-hospital mortality studies in the same institution over the same period in which cerebrovascular accident was the leading cause of death and heart failure was the distant fifth cause. ${ }^{17,27}$ The reason for this difference is uncertain but the in-hospital mortality studies were based on emergency department deaths and the subjects were younger than those in the present study. It is probable that medical attention would be sought earlier for the younger, especially with the dramatic presentation often associated with cerebrovascular-accident. Also, the sometimes chronic clinical course of heart failure may have contributed to fewer deaths being recorded in the emergency-department. The older age recorded in our subjects is in keeping with the reported higher incidence and mortality of cerebrovascular-accident seen in that age group. ${ }^{28}$ Similarly, although the prevalence of cerebrovascular-accident has been reported to be higher in males, it is a relatively more common cause of death in females than in males. ${ }^{19}$ This may explain the equal gender frequency of cerebrovascular-accident recorded in our study, in addition to the fact that our female subjects were significantly older.

The finding of myocardial-infarction in $8.9 \%$ of our subjects is much lower than the prevalence of coronary-artery-disease in autopsied out-of-hospital sudden deaths in China (50.3\%), India (56.9\%) and Ireland (75.0\%). ${ }^{3,29,30}$ It however suggests a possible increasing prevalence of coronary-artery-disease in Nigerians as studies from earlier years had reported prevalence rates ranging from $0 \%$ to $6.3 \%$ in coroner's autopsy cases. ${ }^{9,11,22}$ This apparent in- creasing prevalence is in keeping with the WHO's projected doubling mortality from CAD by year 2020 with $82 \%$ of the contribution expected to be from developing countries. ${ }^{12}$ In addition, the prevalence of myocardial-infarction in our subjects is higher than that reported for in-hospital mortality of the same institution. ${ }^{17,31}$ This difference may be expected as the bulk of mortality from CAD reportedly occur out-of-hospital. ${ }^{3,8,30}$ This is particularly relevant to Nigeria where low patronage of orthodox health facility has been reported, ${ }^{10}$ and may buttress the possibility of an actual higher prevalence of coronary-artery-disease in Nigerians. The equal gender distribution of myocardial-infarction in our study contrasts with the reported higher prevalence in males in other studies.,11,24 This can be explained by the known higher incidence of acute myocardial-infarction in older women (as seen in our study) such that the prevalence in them equals that in men with advancing age. ${ }^{19,32}$ The predominance of heart failure as cause of death following myocardial-infarction in this study is in keeping with reports from other African studies, ${ }^{7,33}$ but differs from the myocardial rupture and repeat infarction reported in a European study. ${ }^{34}$

Cardiomyopathies were infrequent causes of death in our study, similar to previous study in Nigeria, ${ }^{9}$ but more frequent than was reported in a European based study. ${ }^{35} \mathrm{Pul}-$ monary embolism was rare (1.1\%) in this study compared to the prevalence of $10.4 \%$ reported among sudden death cases in one Nigerian study, ${ }^{22}$ but corresponds with that recorded for in-hospital mortality of same institution. ${ }^{17}$ A limitation of this study is the problem of incomplete data, inherent to retrospective studies, necessitating exclusion of such from the study.

\section{Conclusion}

Cardiovascular-related diseases are major contributors to out-of-hospital medical deaths in both men and women, occurring chiefly in those $>60$ years. Hypertensive heart disease and heart failure are the greatest contributors to this cardiovascular-related disease mortality. This pattern differs from that reported for in-hospital mortality. The reasons these deaths occur out-of-hospital is worth exploring. Intensifying hypertension control strategies through focused health education of this vulnerable group may help minimize this preventable loss.

\section{Conflict of interest}

The authors declare no conflict of interest. 


\section{References}

1. Alwan A. Global status report on non-communicable diseases 2010. World Health Organization; 2011.

2. Moran A, Forouzanfar M, Sampson U, Chugh S, Feigin V, Mensah G. The epidemiology of cardiovascular diseases in sub-Saharan Africa: The global burden of diseases, injuries and risk factors 2010 study. Prog Cardiovasc Dis. 2013; 56(3):234-239.

3. Wang H, Yao Q, Zhu S, Zhang G, Wang Z, Li Z, Sun R, Lu C, Li C, Pu J. The autopsy study of 553 cases of sudden cardiac death in Chinese adults. Heart Vessels. 2014; 29(4):486-495.

4. Gillum RF. Coronary heart disease in black populations I. Mortality and morbidity. Am Heart J. 1982; 104(4):839851.

5. Sliwa K, Wilkinson D, Hansen C, Ntyintyane L, Tibazarwa K, Becker A, Stewart S. Spectrum of heart disease and risk factors in a black urban population in South Africa (the Heart of Soweto Study): a cohort study. The Lancet. 2008; 371(9616):915-922.

6. Ojji D, Stewart S, Ajayi S, Manmak M, Silwa K. A predominance of hypertensive heart failure in the Abuja Heart Study cohort of urban Nigerians: a prospective clinical registry of 1515 de novo cases. Eur J Heart Fail. 2013; 15(8):835-842.

7. Anjorin CO, Buba F, Eneh AC. Myocardial infarction at the University of Maiduguri Teaching Hospital, North Eastern Nigeria: A long term review. J Med Sci. 2005; 5(4):358-362.

8. Luepker R.V. Epidemiology of Sudden Death. In: Ornato J.P., Peberdy M.A. (eds) Cardiopulmonary Resuscitation. Contemporary Cardiology. Humana Press, 2005.

9. Rotimi O, Fatusi AO, Odesanmi WO. Sudden cardiac death in Nigerians-the Ile-Ife experience. West Afr J Med. 2004; 23(1):27-31.

10. Bamidele JO, Adebimpe WO, Oladele EA. Knowledge, attitude and use of alternate medical therapy amongst urban residents of Osun State, SouthWestern Nigeria. Afr J Tradit Complement Altern Med. 2009; 6(3): 281-288.

11. Essien OE, Andy J, Ansa V, Otu AA, Udoh A. Coronary Artery Disease and the Profile of Cardiovascular Risk Factors in South South Nigeria:A Clinical and Autopsy Study. Cardiol Res Pract. 2014; 2014:804751. doi: 10.1155/2014/804751.

12. Okrainec K, Banerjee DK, Eisenberg MJ. Coronary artery disease in the developing world. Am Heart J. 2004; 148(1):7-15.

13. McGrw-Hill Concise Dictionary of Modern Medicine. 2002. The McGraw-Hill Companies, Inc.

14. Kirshner T, Anderson R. Cause of Death: Proper Completion of Death Certification. JAMA. 1987; 258: 349-352.

15. Lloyd-Jones D, Adams RJ, Brown TM, Carnethon M, Dai S, Giovanni De Simone MD, et al. AHA statistical update. Heart disease and strokestatistics-2010 update: a report from the American Heart Association. Circulation. 2010; 121:e46-e215.

16. WHO non-communicable disease country profile -Nigeria available@http://www.who.int/nmh/countries/nga_en.pdf.

17. Adegoke O, Iwuala S, Oputa-Onwusa OA. Mortality pattern and causes at the adult medical unit of the accident and emergency department of a tertiary health care facility in Lagos, Nigeria. Nig. Qt. J. Hosp Med. 2016; 26(3): 483-487.

18. Laws of the Federation of Nigeria-Statutory corporations-pensionable officer. availablbe@http:// www.lawnigeria.com/LawsoftheFederation/STATUTORY-CORPORATIONS-PENSIONABLE-OFFICERS-(RETIRING-AGE-LIMIT)- ACT.html

19. Stramba-Badiale M, Fox KM, Priori SG, Collins P, Daly C, Graham I, et al. Cardiovascular diseases in women: a statement from the policy conference of the European Society of Cardiology. Eur Heart J. 2006; 27(8):9941005.

20. Ogah OS, Okpechi I, Chukwuonye II, Akinyemi JO, Onwubere BJ, Falase AO, Stewart S, Sliwa K. Blood pressure, prevalence of hypertension and hypertension related complications in Nigerian Africans: A review. World J Cardiol. 2012; 4(12):327-340. doi: 10.4330/wjc.v4.i12.327. 21. Ekwunife OI, Udeogaranya PO, Nwatu IL. Prevalence, awareness, treatment and control of hypertension in a Nigerian population. Health. 2010; 2(07):731-735.

22. Akinwusi PO, Komolafe AO, Olayemi OO, Adeomi AA. Pattern of sudden death at Ladoke Akintola University of Technology Teaching Hospital, Osogbo, South West Nigeria. Vasc Health Risk Manag. 2013; 9:333-339.

23. Amakiri CN, Akang EE, Aghadiuno PU, Odesanmi WO. A prospective study of coroner's autopsies in University College Hospital, Ibadan, Nigeria. Med Sci Law. 1997; 37(1):69-75. 
24. Aligbe JU, Akhiwu WO, Nwosu SO. Prospective study of coroner's autopsies in Benin City, Nigeria. Med Sci Law. 2002; 42(4):318-324.

25. Yamasaki N, Kitaoka H, Matsumura Y, Furuno T, Nlshinaga M, Doi Y. Heart Failure in the Elderly. Intern Med. 2003; 42: 383-388.

26. Liu MH, Wang CH, Huang YY, Cherng WJ, Wang KW. A correlational study of illness knowledge, self-care behaviors, and quality of life in elderly patients with heart failure. J Nurs Res. 2014; 22(2):136-45.

27. Uzoechina Jr NS, Abiola AO, Akodu BA, Mbakwem A, Arogundade AR, Tijani H, et al. Pattern and outcome of cases seen at the adult accident and emergency department of the Lagos University Teaching Hospital, Idi-Araba, Lagos. Nig. Qt. J. Hosp. Med. 2012; 22(3):209-215.

28. Walker R, Whiting D, Unwin N, Mugusi F, Swai M, Aris E, Jusabani A, Kabadi G, Gray WK, Lewanga M, Alberti G. Stroke incidence in rural and urban Tanzania: a prospective, community-based study. The Lancet Neurology. 2010; 9(8):786-792. doi: 10.1016/S1474-4422(10)701447.

29. Rao D, Sood D, Pathak P, Dongre SD. A cause of Sudden Cardiac Deaths on Autopsy Findings; a FourYear Report. Emerg (Tehran). 2014; 2(1): 12-17.

30. Byrne R., Constant O., Smyth Y, Callagy G, Nash

$\mathrm{P}$, Daly $\mathrm{K}$, et al; Multiple source surveillance incidence and aetiology of out-of-hospital sudden cardiac death in a rural population in the West of Ireland. European Heart Journal. 2008; 29(11): 1418-1423.

31. Mbakwem AC, Oke DA, Ajuluchukwu JNA, Abdulkareem FB, Ale O, Odunlami K. Trends in acute emergency room hypertension related deaths: an autopsy study. Niger J Clin Pract. 2009; 12(1):15-19.

32. Berger J.S, Elliott L, Gallup D, Roe M, Granger CB, Armstrong PW, et al. Sex Differences in Mortality Following Acute Coronary Syndromes. JAMA. 2009;302(8):874882. doi: 10.1001/jama.2009.1227.

33. Pessinaba S, Kane A. Acute coronary syndrome in young Sub-Saharan Africans: A prospectivestudy of 21 cases. BMC cardiovascular disorders. 2013; 13(1):118. doi: 10.1186/1471-2261-13-118.

34. Pouleur AC, Barkoudah E, Uno H, Skali H, Finn PV, Zelenkofske SL, et al. Pathogenesis of sudden unexpected death in a clinical trial of patients with myocardial infarction and left ventricular dysfunction, heart failure, or both. Circulation. 2010; 122:597-602.

35. Bowker TJ, Wood DA, Davies MJ, Sheppard MN, Cary NR, Burton JD, Chambers DR, Dawling S, Hobson HL, Pyke SD, Riemersma RA. Sudden, unexpected cardiac or unexplained death in England: a national survey. QJM: An International Journal of Medicine. 2003; 96(4):269279. 